\title{
CONOCIMIENTO Y APLICACIÓN DE LAS DISPOSICIONES LEGALES-FISCALES RELACIONADAS CON EL COSTO DE VENTAS E INVENTARIOS EN LAS PEQUEÑAS Y MEDIANAS EMPRESAS (PYMES) COMERCIALES, EN HERMOSILLO SONORA.
}

Knowledge and application of the legal-tax provisions related to the Cost of Sales and Inventories in Commercial Small and Medium Enterprises (PyMes), in Hermosillo Sonora.

\author{
Dr. Sergio Félix Enriquez ${ }^{1}$, Dr. Ana Elsa Ortiz Noriega ${ }^{2}$, Dr. Fernando Calles Montijo ${ }^{3}$ \\ ${ }^{1}$ HTTPS://ORCID.ORG/0000-0002-4345-6089 \\ sergio.felix@unison.mx \\ Universidad de Sonora \\ ${ }^{2}$ HTTPS://ORCID.ORG/0000-0001-6379-6366 \\ anaelsa.ortiz@unison.mx \\ Universidad de Sonora \\ ${ }^{3}$ HTTPS://ORCID.ORG/0000-0001-7544-2012 \\ fernando.calles@unison.mx \\ Universidad de Sonora
}

DOI https://doi.org/10.46589/rdiasf.vi35.380

Recibido 4 de marzo 2021.

Aceptado 19 de mayo 2021

Publicado 30 de junio de 2021

\section{Resumen}

El trabajo es parte del resultado de proyecto de investigación: la normatividad contable y disposiciones legales en materia de contribuciones, relacionadas con el control de inventarios y determinación de los costos que impactan en los resultados en las pequeñas y medianas empresas en Hermosillo, Sonora y los reportes financieros correspondientes.

Se presenta un panorama general de la situación de las pymes en México, incluyendo un apartado relacionado con el impacto de la contingencia derivada del COVID 19.

El objetivo planteado es identificar y determinar si las PYMES, aplican las disposiciones fiscales en materia de la valuación y control de inventarios, así como la determinación del costo de ventas. 
La metodología tiene un enfoque cualitativo, de tipo descriptivo y para la recopilación de datos se aplicó un cuestionario a empresas de la Cd. de Hermosillo, Sonora. Utilizando el SPSS, para su análisis.

Los principales resultados encontrados son, que las empresas de este sector, si conocen y aplican las disposiciones fiscales, en el control y valuación de inventarios, así como en la determinación del costo de lo vendido, deduciendo que los resultados que se presentan en los reportes financieros, es el adecuado, considerando como una oportunidad de desarrollo, capacitación y asesorías para el sector de las micros y quienes lo deseen para las pequeñas empresas, profesionalizando su administración y y hacer más eficiente el debido cumplimiento de sus obligaciones fiscales.

Palabras Claves: PYMES, Inventarios, Costo de ventas, normatividad fiscal

\begin{abstract}
The work is part of the result of the research project: accounting regulations and legal provisions on contributions, related to inventory control and determination of costs that impact the results of small and medium-sized companies in Hermosillo, Sonora and the corresponding financial reports. An overview of the situation of SMEs in Mexico is presented, including a section related to the impact of the contingency derived from COVID 19.

The proposed objective is to identify and determine if SMEs apply the tax provisions regarding the valuation and control of inventories, as well as the determination of the cost of sales. The methodology has a qualitative, descriptive approach and for data collection a questionnaire was applied to companies in the city of Hermosillo, Sonora. Using SPSS, for analysis.

The main results found are that the companies in this sector, if they know and apply the tax provisions, in the control and valuation of inventories, as well as in the determination of the cost of what is sold, deducing that the results presented in the reports It is appropriate, considering it as an opportunity for development, training and advice for the bus sector and those who wish it for small companies, professionalizing their administration and making the due fulfillment of their tax obligations more efficient.
\end{abstract}


Keywords: SMEs, Inventories, Cost of sales, tax regulations

\section{Introducción}

Es de suma importancia la existencia de empresarios en la localidad que estén conscientes de las necesidades del control, administración y correcta valuación de sus inventarios, costo de ventas y determinación de resultados y apegado a normatividad y cumplimiento de disposiciones fiscales. En el presente trabajo se analiza la importancia de la correcta valuación del costo de ventas y sus implicaciones en los resultados y preparación de información financiera, con apego a lo dispuesto por las leyes en materia fiscal, en las pequeñas y medianas empresas, las cuales pueden estar organizadas para su funcionamiento, como personas físicas y personas morales o sociedades, se aborda la problemática del costo de ventas e inventarios desde la perspectiva de las disposiciones fiscales en materia de Ley del Impuesto Sobre la Renta (LISR) y Código Fiscal de la Federación (CFF), lo que conlleva a un mejor control de las mercancías, productos o artículos, en las pequeñas y medianas empresas comerciales, factor que influye en la preparación de información financiera, la base para la toma de decisiones, que inciden en el éxito o fracaso de las mismas en el mundo de los negocios. Se pretende demostrar la importancia del problema y el efecto que tiene en la determinación de resultados, de no hacerse apegado a la legalidad, en la materia fiscal, incidiendo en la planeación a futuro del funcionamiento del negocio, en la toma de decisiones, que en ocasiones se efectúa sobre bases erróneas que pueden perjudicarla con implicaciones como situaciones fiscales que le provoquen caer en la ilegalidad, causando infracciones y pago de multas o tan graves como la misma desaparición de la empresa, pérdida de competitividad, calidad en el servicio entre otros. La actual globalización de las economías coloca a las empresas de los países en vías de desarrollo frente a retos importantes y grandes competidores. Otro factor que en la actualidad está afectando al sector empresarial y particularmente a las Pequeñas y Medianas Empresas (PYMES), es el tema de la contingencia sanitaria, que a nivel mundial se padece motivado por el COVID 19, lo cual obliga a este sector de empresas a luchar por sobrevivir económicamente hablando y a la observancia con mayor ímpetu de la normatividad, ya que en situaciones de contingencia, la preparación de la información financiera debe ser diferente que lleve a los usuarios de la información a una mejor toma de decisiones. Los consumidores, que 
tienen actualmente a su disposición una mayor gama de opciones a escoger, esto significa para las empresas, que aspectos tales como el cumplimiento en las entregas, la calidad de los productos, la eficiencia en el uso de capital de trabajo y la disponibilidad de productos, no sean ya, opciones sobre las cuales trabajar, sino más bien una obligación ineludible para lograr sobrevivir. La correcta planeación, administración y control de los inventarios de materias primas, producto terminado, partes y repuestos, tienen un impacto positivo sobre todos los conceptos mencionados anteriormente y son la única respuesta posible de la administración a los retos que enfrentan las empresas productoras, comercializadoras y prestadoras de servicios en la actualidad. La importancia de los inventarios en la toma de decisiones radica en su adecuado control y valuación de los mismos, ya que éstos forman parte importante en el análisis de la información que se prepara y sobre todo que estos se reflejan en los resultados de la empresa, mediante la determinación del costo de ventas y la obtención de la utilidad en ventas. Desde inicios del presente siglo, la tendencia de acuerdo con los censos económicos que se realizan en el país cada cinco años, las Pymes representaban el $98.8 \%$, el $0.9 \%$ medianas y sólo el $0.3 \%$ eran grandes empresas, del total de las entidades económicas censadas, lo cual se ha mantenido a pesar de que el número de empresas se incrementan, es decir, la composición porcentual sigue siendo la misma con respecto a este tipo de unidades micro, pequeñas, medianas y grandes empresas. Así mismo las micros y pequeñas y medianas empresas son las que más empleos generan a nivel nacional y en el entorno regional, que permiten sostener en gran medida, la economía nacional, tienen una mayor participación en el ámbito impositivo ya que en conjunto generan una mayor recaudación de impuestos. En Sonora, estado donde se ubica la ciudad de Hermosillo, la tendencia es similar, ya que, a nivel nacional de acuerdo con los últimos censos realizados, las pequeñas y medianas empresas representan el $2.22 \%$ del total nacional, su personal ocupado es el $2.73 \%$ del producto interno bruto estatal, y del 1.95\% a nivel nacional. A nivel estatal las Mipymes representan el 88\% del total de las unidades económicas generando el $41.7 \%$ del empleo. En particular la pequeña empresa representa el 9. 16\% del total de las empresas estatales. En la ciudad de Hermosillo el total de empresas representan el $28.8 \%$ del total a nivel estatal y el sector comercio aglutina el $27.9 \%$ del total de los comercios. En general en el estado de Sonora y en Hermosillo en particular, el sector comercio cuenta con el $70.86 \%$ de los establecimientos, el de servicios el $27.91 \%$ y la 
industria el $1.23 \%$, siendo el comercio al por menor el que más establecimientos cuenta con un $53.82 \%$ por lo que se hace importante el estudio de este sector empresarial y un adecuado conocimiento tanto de la normatividad aplicable como disposiciones fiscales por parte de alumnos y docentes para desde el punto vista profesional otorgar una adecuada asesoría profesional.

\section{Objetivos}

\section{General:}

Determinar que las pequeñas empresas comerciales de Hermosillo, Sonora, cumplen con las disposiciones fiscales vigentes en materia de valuación de inventarios y determinación de costo de ventas

\section{Específicos:}

- Identificar las disposiciones fiscales aplicables a la valuación de inventarios y la determinación del costo de ventas.

- Conocer si las pequeñas empresas comerciales cumplen con lo dispuesto en las normas fiscales, en materia de costo de ventas y valuación de inventarios.

\section{Descripción del problema}

En la actualidad, la gestión de las empresas debe considerar la eficiencia, competencia, evaluación de resultados y la toma de decisiones estratégicas en búsqueda de la competitividad. El concepto del costo se debe tener presente para el logro de un objetivo, al hacerlo se debe considerar el cumplimiento de lo dispuesto para tal fin por la legislación fiscal y la normatividad contable que rige a las entidades económicas. En este sentido es de vital importancia que las empresas generen información financiera, cumplan con la normatividad contable establecida y el pago de impuestos correspondientes. Tanto el rubro de inventarios y el costo de ventas como se ha mencionado con anterioridad, es uno de los rubros más importantes entre los activos o bienes de una empresa, porque aparte de su control es importante su correcta valuación ya que esto impacta en la determinación del costo de ventas y por lo tanto en la determinación de resultados y por ende en el correcto cumplimiento de las obligaciones fiscales. Es por estas razones que es importante hacerse las siguientes preguntas de investigación: 1. ¿Las PYMES, se apegan a las disposiciones fiscales 
para la correcta valuación de sus inventarios? 2. ¿Este tipo de organizaciones determinan adecuadamente el costo de sus ventas, apegado a la normatividad fiscal y por ende la determinación adecuada de sus resultados?

\section{Antecedentes}

\section{Las pequeñas y medianas empresas}

En México como en el resto del mundo, el emprendimiento ha tomado gran relevancia por lo que significa y el impulso que se da en la educación el contar con una empresa propia y como un factor importante que fortalece esta idea, es la falta de oportunidades de contar con empleos debidamente recompensados económicamente, por lo que opta por iniciar su propio negocio; en base a lo anteriormente expresado se considera que toda empresa normalmente surge como una pequeña organización, algunas de ellas lográndose desarrollar de tal manera que alcanzan dimensiones de grandes consorcios, en cuanto a la generación de riqueza, empleos, acumulación de fortunas, siendo éstas, aquellas que tuvieron la visión de fijar metas a través de la organización y la planeación, es decir mediante una adecuada administración.

Como se menciona en párrafos arriba, en tiempos modernos, para hacer más eficiente la administración de una entidad económica y poder lograr los objetivos planteados, se requiere de eficiencia, competencia, evaluación de resultados, esto siempre y cuando se cuente con planes a futuro pero por lo general, al iniciar, se centralizan las funciones en una sola persona, no cuentan con procesos sistematizados, objetivos, planes y estrategias a corto, mediano y largo plazo, ni con una administración profesional. Además, tienen poco capital fijo y sus técnicas de trabajo son simples. En algunos casos, otra peculiaridad de este tipo de empresas, es la incorporación de familiares como trabajadores de tiempo completo o parcial, sin que éstos perciban ni el salario, ni las prestaciones correspondientes; sí consideramos que estas empresas tienen escaso desarrollo tecnológico, altos costos de operación, baja calidad y productividad, entonces, los acelerados cambios tecnológicos hoy presentes en todo el mundo, las obligan a realizar grandes inversiones y a mejorar sus sistemas de soporte, lo que las posibilita a acceder a un equipo flexible mejor adaptado y mejorar su capacidad administrativa y de innovación, ante esto es difícil que sobrevivan ya que no tienen acceso a créditos para la inversión que todo lo anterior requiere. Se suma también, 
los cambios en los gustos del consumidor, que antes deseaba productos y servicios estandarizados y masivos, y ahora están demandando productos cada vez más estilizados y personalizados, y sobre todo el uso de la tecnología para la adquisición de productos, y el pago correspondiente es condición de las que carecen muchas de este tipo de empresas, lo cual se profundiza con los impactos que ha provocado la contingencia de salud, esto las torna más vulnerables frente a la competencia de las grandes empresas nacionales e internacionales. Todas las características, arriba mencionadas, influyen no sólo para que las micro, pequeñas y algunas medianas empresas crezcan (Mipymes), sino para que sobrevivan. A esto hay que sumar que en muchas ocasiones los trabajadores no perciben todas las prestaciones que señala la ley, lo que hace que los costos fijos de las empresas se vean reducidos y les permita sobrevivir en condiciones adversas, como la actual.

Sin embargo, es una realidad que en el país las micros y pequeñas empresas representan aproximadamente el $99.6 \%$ de la empresa establecida en la economía mexicana, tal como se demuestra en el cuadro de información No.2, que generan una gran cantidad de empleos, están en la incertidumbre si sobrevivirán o no a la época de globalización que vivimos. También es un hecho que está en manos de este tipo de empresarios, parte de la solución de este grave problema ya que con creatividad, organización e información confiable que ellos mismos generan, están en posibilidades de tomar las mejores decisiones dentro de su organización, que no solo les ayude a sobrevivir, sino a desarrollarse y crecer dentro su actividad, la intención de este trabajo es concientizar a los empresarios, de la fuente importante de sus actividades como comerciantes, que son los inventarios de mercancía y su control es base importante para su desarrollo.

De acuerdo con la página de pulso PYME y con información de Nacional Financiera, S.C. y la Secretaría de Economía, el sector de las PYME emplea metodologías de trabajo en base a las experiencias de sus dirigentes y propietarios siendo sus procesos de trabajo de manera empírica, sin estar basadas en las técnicas, métodos y sistemas tecnológicas que la actualidad empresarial tiene a su disposición proporcionada por los expertos, lo cual perjudica el desarrollar un plan de negocios. (https://www.pulsopyme.com/como-operan-en-la-actualidad-las-pymes-en-mexico/) 


\section{Clasificación y participación de las empresas en México}

Diferentes organismos en el país clasifican a las empresas en cuanto a su tamaño y participación, considerando varios factores como el giro, cantidad de empleados con los que cuenta, monto de los ingresos, entre otros. La Secretaría de Economía y el Instituto Nacional de Estadística y Geografía (INEGI) son los principales referentes en este sentido en el país.

De acuerdo con la Secretaría de Economía, el tamaño de las empresas se clasifica de acuerdo al siguiente cuadro:

Cuadro No. 1 Clasificación de Empresas por número de empleados e ingresos anuales

\begin{tabular}{|l|l|l|l|l|}
\hline Sector/Tamaño & $\begin{array}{l}\text { Industria } \\
\text { (Empleados) }\end{array}$ & $\begin{array}{l}\text { Comercio } \\
(\text { Empleados) }\end{array}$ & $\begin{array}{l}\text { Servicios } \\
\text { (Empleados) }\end{array}$ & $\begin{array}{l}\text { Ingresos Anuales } \\
\text { (Millones pesos) }\end{array}$ \\
\hline Microempresa & $0-10$ & $0-10$ & $0-10$ & 4.0 \\
\hline Pequeña Empresa & $11-30$ & $11-30$ & $11-30$ & $4.0-100.0$ \\
\hline Mediana Empresa & $31-100$ & $31-100$ & $31-100$ & $100.0-250.0$ \\
\hline Grande Empresa & $101-251$ & $101-251$ & $101-251$ & Más 250 millones \\
\hline
\end{tabular}

Fuente: https://www.gob.mx/ secretaria de economía

El impacto que las empresas pequeñas tienen en la economía del país es demasiado grande, como para no darle la importancia requerida en su administración, tal y como se muestra en el siguiente cuadro:

Cuadro No. 2 Participación porcentual de las empresas en la Economía Nacional

\begin{tabular}{|l|l|l|l|}
\hline Tamaño & Empresas & Personal Ocupado \\
\hline & Número & Participación (\%) & Participación \\
\hline Microempresa & $4{ }^{\prime} 431,221$ & 95.97 & 45.6 \\
\hline Pequeña empresa & 147,438 & 3.19 & 15.0 \\
\hline Mediana empresa & 27,985 & 0.62 & 17.0 \\
\hline Grande empresa & 10,220 & 0.22 & 22.4 \\
\hline Total & $4^{\prime} 616,864$ & 100. & 100.0 \\
\hline
\end{tabular}

Fuente: https://www.inegi.org.mx/ Censos económicos 2019 
De acuerdo con el cuadro No. 2 la microempresa es la de mayor participación con alto porcentaje del $95.97 \%$ en el mercado nacional y si se considera el sector pymes, el porcentaje es del $99.78 \mathrm{y}$ generando el $77.60 \%$ de los empleos formales en el país y que generan riqueza como se ve en el siguiente cuadro relacionado con el producto interno bruto (PIB) en el territorio nacional.

\section{Cuadro No. 3 Generación de Empleos y el PIB por sector.}

\begin{tabular}{|l|l|l|}
\hline Tamaño de empresa & PIB & Personal Ocupado \\
\hline Microempresa & $15 \%$ & 45.6 \\
\hline Pequeña empresa & $14 \%$ & 15.0 \\
\hline Mediana empresa & $22 \%$ & 17.0 \\
\hline Grande empresa & $49 \%$ & 22.4 \\
\hline Total & $100 \%$ & 100.0 \\
\hline
\end{tabular}

Fuente: https://www.inegi.org.mx/ Censos económicos 2019

Como se observa las Mipyme's generan el 51\% del PIB de la economía mexicana lo cual impacta en el 77.6\% de los empleos generados en el México, considerándose un importante sector el cual se deber fortalecer desde el interior de la empresa en cuanto a su manejo, organización y control en sus procesos de producción, contables y financieros, esto último a través de la profesionalización y observancia de la normatividad contable correspondiente, lo cual le ayuda y le fortifica en la toma de decisiones que coadyuvan en su presencia, crecimiento y subsistencia. En relación a la participación por sectores, industria, comercio y servicios, el dato del último censo muestra la siguiente información.

Cuadro No. 4 Participación de las empresas por sector

\begin{tabular}{|l|l|l|l|}
\hline Sector/Tamaño & Industria & Comercio & Servicios \\
\hline Microempresa & 544,927 & $2^{\prime} 195,350$ & $1^{\prime} 702,770$ \\
\hline Pequeña Empresa & 25,165 & 42,178 & 71,008 \\
\hline Mediana Empresa & 6,048 & 9,326 & 10,660 \\
\hline Grande Empresa & 3,688 & 1,461 & 4,283 \\
\hline Total & 579,828 & $2^{\prime} 248,315$ & $1^{\prime} 788,721$ \\
\hline
\end{tabular}


Fuente: Fuente: https://www.inegi.org.mx/ Censos económicos 2019

En el cuadro anterior se observa la gran participación sobre todo la micro empresa en cada uno de los sectores de la economía que, aunado a la pequeña y mediana empresa, refleja la importancia que tienen las Mipyme's en la generación de riqueza en el territorio nacional.

A nivel nacional en el presente siglo, la cantidad de unidades económicas o establecimientos ha venido creciendo, considerando aquellas empresas que tienen varias unidades o sucursales a lo largo del país, ya que de acuerdo a los últimos 4 censos como se manifiesta en la siguiente gráfica.

\section{Gráfica No. 1}

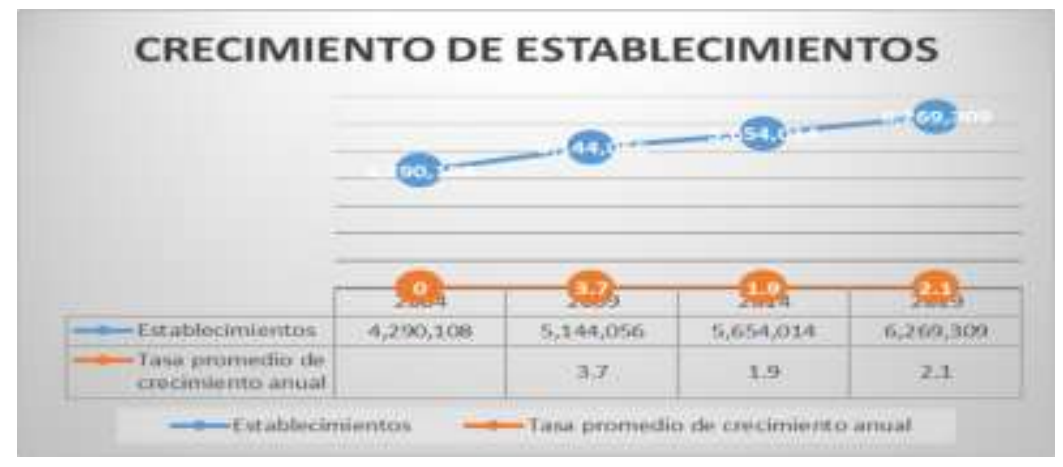

Fuente: https://www.inegi.org.mx/ Censos económicos 2019.

Se reconoce y es una realidad, que en tiempos de contingencia causada por el Covid-19 estas empresas han resultado afectadas y han tenido que despedir personal, cerrar negocios ya sea de manera temporal o definitiva y que han impactado en el crecimiento durante el año de 2020, pero se confía que sobre todo el sector comercio que es uno de los sectores más golpeados por la pandemia, se reponga más rápidamente como se explica en párrafos posteriores.

En Sonora no es distinta la participación de las empresas por tamaño y sector como lo vemos en el siguiente cuadro: 
Cuadro No. 5. Participación de las empresas en Sonora por sector

\begin{tabular}{|c|c|}
\hline Sector & Unidades \\
\hline Comercio & 33,844 \\
\hline Industria & 13,442 \\
\hline Servicio & 45,192 \\
\hline Total & 92,478 \\
\hline
\end{tabular}

Fuente: Fuente: https://www.inegi.org.mx/ Censos económicos 2019

Sonora tiene una participación en el mercado nacional equivalente al $2.08 \%$ en cuanto al total de unidades empresariales, el cual se cuenta $0.87 \%$ de micro empresas del total nacional, $2.07 \%$ de pequeñas empresas el $1.07 \%$ para medianas empresas y $1.19 \%$ para grandes empresas. Las micro, pequeñas y medianas empresas se pueden considerar como la base de la economía sonorense, tanto en número de unidades económicas, como del total de establecimientos $(90,642)$, Hermosillo registró el mayor porcentaje con $31.7 \%$ por los miles de empleos que generan. Del total de establecimientos, $92.5 \%$ ocupó de 0 a 10 personas, y las ramas de actividad que sobresalieron son abarrotes y alimentos al por menor y la preparación de alimentos y bebidas.

Dentro de la nueva temática de los censos económicos 2019, se incluyó el tema del uso de la tecnología o internet, es importante señalar que el $95.7 \%$ no utilizó internet para comprar o vender lo cual significa un gran reto y oportunidad de crecer sobre toda para las pequeñas empresas, pero un dato muy importante y está relacionado con este trabajo y con el sector profesional de la contaduría pública, es que la mayoría de los establecimientos no llevan un registro contable de sus operaciones sobre todo para los gastos e ingresos, y dentro de estos gastos se incluye el costo de ventas como parte de los egresos. Se menciona que el 29.9\% cuenta con un sistema contable propio, el $25.0 \%$ le paga a un profesionista de la contaduría pública por sus servicios y lo relevante es que el $40.2 \%$ no lleva un registro contable y el 4.9 cuenta con un sistema contable desarrollado por terceros o software comerciales.( https://www.inegi.org.mx/ Censos económicos 2019) 


\section{Efectos del Covid 19 en las PYMES y la observancia de las NIF en México.}

Como se mencionó en renglones anteriores, la pandemia ocasionada por el COVID 19, impactó desfavorablemente al sector económico de todo el mundo y México, no fue la excepción, Estudios realizados por INEGI, a través de encuestas, manifiesta en su comunicado de prensa, la ECOVID-IE en su segunda edición que el 86.6\% de 1’873,564 empresas en el país tuvieron alguna afectación a causa de la pandemia, casi 7 puntos porcentuales menos con respecto a la primera edición en la que el $93.2 \%$ de las empresas reportó alguna afectación, siendo los ingresos el principal tipo de afectación

De los 4.9 millones de establecimientos del sector privado y paraestatal registrados en los censos económicos de 2019, el $99.8 \%$ son micros, pequeños y medianos, sobrevivieron 3.9 millones que significa el 79.19 , poco más de un millón que es $20.81 \%$ cerraron sus puertas definitivamente y nacieron 619,443 nuevos establecimientos que representan el $12.75 \%$ de los negocios en el país.

(https://inegi.org.mx/contenidos/saladeprensa/boletines/2020/OtrTemEcon/ECOVID-

\section{IE_DEMOGNEG.pdf)}

En cuanto al aspecto contable y la normatividad contable, Deloitee en su publicación del mes de marzo del presente año, menciona que es importante resaltar algunos aspectos claves a considerar por parte de las empresas a nivel mundial al preparar sus estados financieros ya que los impactos financieros son relevantes y significativos y tener implicaciones contables para dichas empresas entre los cuales se mencionan entre otros:

Interrupción en la producción

Reducción de ventas, y utilidades, así como en la productividad

Cierre de establecimientos

Problemas de asistencia y recortes de personal

Problemas de financiamiento

Por lo anterior se deben considerar los efectos del Covid 19 y su impacto negativo en la economía debiendo analizar los efectos que se tendrán en la información financiera para lo cual 
también deben tomar en cuenta lo relacionado con el aspecto contable y revelación relacionada con:

- Valoración de inventarios y por ende el costo de ventas

- Negocio en marcha,

- Determinación de resultados, utilidad o pérdida

- Consideraciones fiscales, entre otros.(https://www2.deloitte.com/content/dam/Deloitte/cr/Documents/audit/documentos/I FRS-in-Focus--Enfermedad-COVID-19.pdf)

Para la Dra. Tapia Iturriaga en su publicación del mes de abril de 2020 se debe analizar y tomar en cuenta la normatividad contable para la preparación de información financiera durante esta contingencia, en particular con la NIF A4, relativa a características de la información destacando la confiabilidad y relevancia para que la información sea objetiva y verificable considerando el impacto que tendrá la pandemia sobre la elaboración de información financiera, considerando la NIF A-2 Postulado de negocio en marcha y la NIF A-1 en lo relativo al juicio profesional (http://imcp.edu.mx/)

A nivel mundial como a nivel del país, la situación actual que la economía mundial enfrenta, tanto las Normas Internacionales (IFRS), como las Normas de Información Financiera (NIF) en México, permiten reconocer en las empresas, los efectos que en su información financiera, pueda tener esta situación actual y futura que se padece, ya que tanto las IFRS como las NIF, establecen las normas de valuación, presentación y revelación que deben realizar las empresas en sus informes financieros correspondientes al año de 2019 y 2020 para revelar los posibles efectos de la pandemia. Así lo señala la publicación de Mazar en México (https://www.mazars.mx/Paginainicial/Insights/Covid-19-Reflexiones-de-Mazars/Implicaciones-Contables-en-los-EEFF-2019$\underline{2020)}$

De igual manera el CINIF, en su reporte técnico No. 48/RT-2020 de abril de 202, del Centro de Investigación y Desarrollo (CID) del CINIF, menciona que el impacto de la pandemia de coronavirus es desigual y grave en todos los sectores económicos, el principal es la disrupción en el crecimiento económico en todo el mundo, por lo que en dicho reporte menciona las posibles repercusiones que puedan generarse por la pandemia son situaciones ya previstas en las NIF 
mexicanas, adicional a las varias consideraciones contables específicas sobre impactos en las valuaciones de los activos y pasivos individuales de la entidad, es necesario evaluar la capacidad de la entidad de enfrentar la importante interrupción en las operaciones habituales provocada por la pandemia y poder continuar como negocio en marcha. Los principales impactos que se reconocen, también son:

Reducción en las ventas y ganancias, reducción o aumento en los precios de mercado de los bienes, afectando a sus inventarios, y por ende a sus costos.

Reducción de la disponibilidad de personal

Por todo lo anterior es importante considerar lo establecido en la NIF B13 que establece que, a la fecha de los estados financiero se pueden identificar hechos posteriores que requieran ajuste y revelación o solo requiere revelación, con el fin de medir el impacto en los estados financieros de estos años. (https://www.cinif.org.mx/anuncios/reporte/Reporte_Tecnico_312016.pdf)

En materia fiscal, los efectos de la pandemia no fueron lo suficientemente impactantes, para que las autoridades del país, sobre todo a nivel federal, consideraran disposiciones fiscales que ayudarán a las empresas y sobre todo a las pequeñas y medianas, así como apoyos económicos, para que este sector pudiera contener dichos impactos e incluso para que pudieran sobrevivir. En cuanto a las entidades federativas, cada una de ellas diseñó estrategias particulares, de acuerdo a sus recursos disponibles que en algo apoyaron a la economía regional.

\section{Las disposiciones legales y fiscales con respecto al costo de ventas e inventarios.}

Un factor que ayuda a las PYMES a crecer y sobrevivir en el ámbito en que se desempeñan, es el de una buena administración, que los propietarios, administradores o responsables, estén profesionalmente preparados para hacerlo, pero igual de importante es que reconozcan la importancia de la observancia de las disposiciones legales y sobre todo las fiscales, para que sus organizaciones no tengan problemas en la marcha de la empresa y líos legales que impacten en su desarrollo.

Indudablemente que el control de los inventarios y por ende la determinación del costo de ventas se reflejan en los resultados de las operaciones que realiza una empresa y en la base gravable 
para el pago de las contribuciones como lo es el impuesto sobre la renta, ya que, en la mayoría de los casos, sobre todo en las actividades empresariales que desarrollan tanto personas físicas como morales, que son las figuras legales en las cuales se pueden constituir las pymes, es el origen para su pago.

Desde la Constitución política de los Estados Unidos Mexicanos se establece la obligación para todos los mexicanos del pago de impuestos citado de la siguiente manera:

El art. 31 de la Constitución en su frac IV menciona que es obligación de todos los mexicanos: "Contribuir para los gastos públicos, así de la Federación, como de los Estados, de la Ciudad de México y del Municipio en que residan, de la manera proporcional y equitativa que dispongan las leyes". (CPEUM).

Siendo la Constitución la ley máxima del país, de ella emanan todas las leyes y reglamentos para hacerla cumplir, como sería el caso de las leyes fiscales, que establece la forma y término que se habrá de contribuir al gasto público.

A continuación, se mencionan algunas disposiciones de este tipo, relacionadas con el control de inventarios y la determinación del costo de ventas, directamente relacionados con la determinación de resultados y pago de impuesto sobre la renta, como parte de la importancia que deben considerar la administración de las pequeñas y medianas empresas, a que se refiere este trabajo.

\section{Código de Comercio (CdeC).}

El código de comercio mexicano impone a todas las personas que se dedican al comercio, en su título segundo de las obligaciones comunes a quienes profesan el comercio, según la fracción IV del artículo 16, a llevar un sistema de contabilidad conforme al artículo 33 del mismo código (Art. 16, Código de Comercio).

El capítulo III del Código se refiere a la contabilidad mercantil y en el anteriormente citado artículo 16, menciona entre otras disposiciones que el comerciante está obligado a llevar y mantener un sistema de contabilidad que puede llevarse mediante instrumentos, recursos y sistemas de registro y procesamiento que mejor se acomoden a las características particulares del negocio pero que permitan identificar las operaciones individuales, permita la preparación de estados financieros que se incluyan en la información financiera, recordando que en este apartado 
se incluyen los inventarios en el estado de posición financiera y el costo de ventas en el estado de resultados.

Este mismo artículo menciona que se deben incluir los sistemas de control y verificación internos necesarios para impedir la omisión del registro de operaciones, para asegurar la corrección del registro contable y la corrección de las cifras resultantes. (Art. 33, Código de Comercio)

En este último párrafo se puede considerar los controles referentes a los inventarios como las fórmulas de asignación del costo individual y los sistemas de costeo establecidos.

Por su parte la Ley General de Sociedades Mercantiles, solo refiere el compromiso de parte de los comerciantes que se constituyan como personas morales, a través de sus administradores, la obligación de presentar información financiera, establecido en el artículo 172, y como parte de esa información como lo son el balance general, estado de resultados, estado de cambios en el capital contable y el estado de flujo de efectivo, así como un informe que explique las principales políticas y criterios contables y de información seguida en su preparación (Art.172 LGSM), pudiéndose considerar en este apartado las políticas y procedimientos en el control de inventarios y por consecuencia la determinación del costo de ventas.

\section{Leyes Fiscales.}

El estado mexicano cuenta con una gran diversidad de leyes emanadas de la constitución política mexicana y el cumplimiento de contribuir al gasto público mencionado anteriormente, está regulado por leyes fiscales y otras emanadas de dicha constitución, como lo es el código fiscal federal, considerado como el ordenamiento jurídico que define los conceptos fiscales fundamentales que rigen todas las leyes fiscales, también cada una de las leyes y sus reglamentos que establecen cada uno de los impuestos en México.

El código fiscal de la federación (CFF) es un compendio de diversos aspectos fiscales, cuyo objetivo es determinar las contribuciones y las diversas obligaciones que se deben cumplir en relación con índole federal de las obligaciones y derechos de las autoridades y contribuyentes (Arreguin, 2020)

En relación al control de inventarios y costo de ventas, el código fiscal de la federación, establece en el artículo 28 que todas las personas que estén obligadas a llevar contabilidad, como sería el caso de las PYMES, deberán observar lo siguiente. 
En la fracción I, inciso A) menciona: "Los libros, sistemas y registros contables, papeles de trabajo, estados de cuenta, cuentas especiales, libros y registros sociales, control de inventarios y método de valuación, discos y cintas o cualquier otro medio procesable de almacenamiento de datos, los equipos o sistemas electrónicos de registro fiscal y sus respectivos registros, además de la documentación comprobatoria de los asientos respectivos, así como toda la documentación e información relacionada con el cumplimiento de las disposiciones fiscales, la que acredite sus ingresos y deducciones, y la que obliguen otras leyes; en el Reglamento de este Código se establecerá la documentación ( Código Fiscal de la Federación Cámara de Diputados del H. Congreso de la Unión Secretaría General Secretaría de Servicios Parlamentarios Última Reforma DOF 08-12-2020.)

Como se ve existe el compromiso y obligación mediante el sistema de contabilidad, el control de inventarios, así como el método de valuación su registro contable y documentación comprobatoria.

Por otra parte el artículo 32-F regula el proceder de los contribuyentes al destruir parte de su mercancías, registrada como inventarios y que de acuerdo con las disposiciones fiscales hayan perdido su valor por deterioro u otras causas, y para ejercer este derecho, cuando se trate de bienes básicos como alimentación o de salud humana y cuyo costo de adquisición lo haya deducido para efectos del impuesto sobre la renta, están obligados, antes de destruirlas a ofrecerlas en donación a instituciones dedicadas a la atención de requerimientos básicos de subsistencia en la materia. (Art. 32-F, CFF)

El no cumplimiento de las obligaciones fiscales con respecto a los inventarios, es causa de multa, como lo establece el mismo código en su artículo 55, que menciona que la autoridad puede establecer presuntivamente la utilidad fiscal de los contribuyentes, por los que se deban pagar impuestos, cuando, entre otros casos: no presenten, los libros y registros de contabilidad, así como la documentación comprobatoria, omitan el registro de compras, así como la alteración del costo en más del $3 \%$ de lo declarado en el ejercicio.

Registren compras no realizadas, así como la omisión y alteración en el registro de existencias que deben figurar en los inventarios o registren las existencias a precios distintos de los costos de adquisición, siempre y cuando el importe exceda del 3\% del costo de los inventarios. Y 
un punto muy importante con respecto a los inventarios, no cumplan con las obligaciones sobre valuación de inventarios o no lleven procedimientos de control de los mismos (Art. 55, CFF) También el artículo 58-A establece que las autoridades fiscales pueden modificar los resultados declarados de acuerdo con la LISR, en cuanto a la presuntiva del precio de los bienes enajenados, cuando las operaciones se pacten a un precio menor al de mercado o el costo de adquisición sea mayor a dicho precio, así como cuando la enajenación se realice al costo a menos del costo a excepción de que el contribuyente compruebe que la enajenación se hizo al precio de mercado en la fecha de la operación o que la mercancía haya sufrido algún deterioro motivada por diversas causas.

En el título cuarto relacionado con las infracciones y delitos fiscales, en su capítulo I en el artículo 83, establece que son infracciones relacionadas con la obligación de llevar contabilidad, específicamente en la fracción II, menciona "no llevar algún libro o registro especial a que obliguen las leyes fiscales: no cumplir con las obligaciones sobre valuación de inventarios o no llevar el procedimiento de control de los mismos, que establezcan las leyes fiscales.

\section{Reglamento del Código Fiscal de la Federación. (RCFF)}

Por su parte el reglamento del código fiscal de la federación en el Capítulo IV, habla de la contabilidad, y en la fracción A menciona cuáles son los documentos que integran la contabilidad de una empresa. En la fracción X del artículo 33, pide identificar los bienes adquiridos o producidos los correspondientes a materias primas y productos terminados, así como los enajenados y los destinados a donación o en su caso a la destrucción. (Art. 33 R.C.F.F) y este mismo artículo menciona la obligación de establecer por centro de costos, identificando las operaciones, actos o actividades de cada sucursal o establecimiento.

Con respecto a los inventarios, en la fracción XV del artículo 33 menciona que los registros de inventarios de mercancías, materias primas, productos en proceso y terminados, en los que se llevará control sobre los mismos, que permitan identificar cada unidad, tipo de mercancía o producto en proceso y fecha de adquisición o enajenación según se trate, así como el aumento y disminución en dichos inventarios la existencia al inicio y al final de cada mes y al cierre del ejercicio fiscal. El control de inventarios deberá identificarse el método de valuación utilizado y la 
fecha a partir de cuándo se usa, ya sea primeras entradas primeras salidas, ultimas entradas primeras salidas, costo identificado, costos promedios o detallista, según se trate. (Art. 33, R C.F.F.)

En este caso se puede identificar una discrepancia con las Normas de Información Financiera, en cuanto a los métodos de valuación, ya que las NIF, consideran como fórmulas de asignación del costo individual, solo al PEPS, Costo Promedio y costos identificados.

\section{Ley del Impuesto Sobre la Renta (LISR), su reglamento y los inventarios y el costo de lo vendido.}

En materia de contribuciones, que se relacionan con los inventarios y el costo de la mercancía vendida, es el impuesto sobre la renta, uno de los más importantes en el país que genera un alto porcentaje de ingresos al fisco, y por lo tanto uno de los más fiscalizados por parte de la entidad. El rubro de inventarios es muy importante dentro de los activos de una empresa ya que, tratándose de empresas comercial, es el eje de las actividades que generaran ingresos y debe ser de los de mayor control por la administración de la entidad, para el fisco de igual manera es importante su control y fiscalización ya que de su manejo depende el costo de ventas y por ende la determinación de resultados, base para la causación del impuesto sobre la renta.

Tanto la ley como su reglamento en materia de renta, consideran algunas disposiciones en relación a estos rubros como a continuación se hace referencia.

En el capítulo II de la LISR, habla de las deducciones de las personas morales y en la sección I de las deducciones en general, en relación con inventarios y el costo de ventas, en el artículo 24 fracc. I establece que los contribuyentes pueden deducir las devoluciones que se reciban de mercancías, así como las bonificaciones que hagan en el ejercicio y que también pueden deducir de los ingresos para efecto del cálculo del ISR, el costo de lo vendido, de acuerdo al fracc. II de este mismo artículo, así mismo que para que puedan ser deducidos como costo de adquisición de las mercancías deben corresponder al valor de mercado no siendo deducible el excedente. (Art. 25, LISR) por lo que la empresa debe tener la responsabilidad de controlar y valuar sus inventarios al costo correcto, establecido en la ley incluyendo cuando se trate de importaciones.

Como requisitos de deducibilidad, en artículo 27, establece algunas condiciones como la fracción IV, que deben estar debidamente registradas en contabilidad, la fracción XIII, que el costo de 
adquisición declarado sea el de mercado y siendo de importación, cumpla con los requisitos para hacerlo,

Por otra parte, la fracc. XX, menciona que las mercancías que se tengan en existencia y que hayan sufrido algún deterioro por causas no imputables al contribuyente y que hubieran perdido su valor, debe deducirse de los inventarios así mismo este tipo de mercancías puede destruirse pero antes puede ser ofrecido en donación a entidades que se dediquen a recibir donativos, previamente autorizadas, para destinarlos a la subsistencia y atención, relacionadas con la alimentación, vestido, vivienda y o salud de sectores, personas, comunidades o regiones de escasos recursos, tal y como se regula en el artículo $32 \mathrm{~F}$ del CFF, mencionado anteriormente.

Un concepto muy importante, en la Frac. XXVIII, establece que no son deducibles los anticipos por compra de mercancías, materia prima o producto terminado o semiterminado o por los gastos relacionados directa o indirectamente con la producción y dichos anticipos tampoco formarán parte del costo de lo vendido de la mercancía (Art. 28, LISR)

Con respecto al costo de lo vendido, la LISR, tiene la sección III, sus disposiciones como en el art. 39 dice que el costo de la mercancía que se enajene, así como el de las que se integren al final del ejercicio, se determinará conforme al sistema de costeo absorbente, sobre la base de costos históricos predeterminados. En todo caso, el costo se deducirá en el ejercicio en el que se acumulen los ingresos. (Art. 39, LISR)

Para efectos de la ley el costo en las empresas comerciales, se integra con los siguientes conceptos,

- Costo de adquisiciones netas, es decir ya deducidas las devoluciones, bonificaciones y descuentos

- Los gastos incurridos en las adquisiciones, que sean necesarias para dejarlas en condiciones de venderlas.

Otras actividades podrán también deducir, la compra de materia prima, productos semiterminados

o terminados, disminuidas de devoluciones, descuentos y bonificaciones, los gastos, y las remuneraciones relacionadas con la producción, entre otras.

Para determinar el costo de lo vendido se deducirá el correspondiente a la mercancía no enajenada en el mismo periodo, es decir, el inventario final. (Art. 39, LISR). 
Debe haber consistencia en los métodos y la misma ley establece que para determinar el costo de lo vendido de las mercancías, se deberá aplicar el mismo procedimiento en cada ejercicio durante un periodo de al menos cinco años y solo puede variarse siempre y cuando se cumpla con los requisitos que se establezcan en el reglamento de la misma LISR (Art.39 LISR). La revaluación de los inventarios y el costo de ventas no tienen efectos fiscales.

Como se observa es el mismo mecanismo establecido por la normatividad contable, para efectos de determinar la utilidad conforme dichas disposiciones contables.

De acuerdo con el artículo 41 de la LISR, se cuenta con cuatro métodos de valuación de inventarios, siendo éstos:

- Primeras entradas primeras salidas (PEPS)

- Costo identificado

- Costo promedio

- Detallista.

Como se hizo la aclaración al hablar del CFF, también en la ley existe una pequeña discrepancia con las Normas de Información Financiera (NIF), en cuanto a los métodos de valuación de inventarios, primeramente, las NIF, los considera como fórmulas de asignación del costo individual de los inventarios y solo reconoce los tres primeros, siendo el detallista un método de valuación de inventarios, al igual que el costo de adquisición y costo estándar.

Cuando se utilice el PEPS, se deberá llevar por cada tipo de mercancía y por unidad, sin que pueda ser de forma monetaria. Para el costo identificado puede utilizarse cuando se pueda identificar por número de serie y costos que excedan $\$ 50,000.00$ y cuando se opte por el sistema detallista deberán valuar los inventarios al precio de venta disminuido del margen de utilidad bruta que se tenga en el ejercicio conforme a lo establecido en el reglamento de la ley. (Art. 41, LISR) Los contribuyentes pueden utilizar métodos diferentes contablemente, pero deben llevar un control de la diferencia entre éste y el método fiscal que se aplique y la cantidad a determinar entre los dos no será acumulable o deducible, para efecto del pago de impuestos.

En el artículo 42, menciona que cuando el costo de las mercancías, sea superior al precio de mercado o reposición, podrá considerarse el que corresponda de acuerdo a lo siguiente: 
I. El de reposición, sea éste por adquisición o producción, sin que exceda del valor de realización ni sea inferior al neto de realización.

II. El de realización, que es el precio normal de enajenación menos los gastos directos de enajenación, siempre que sea inferior al valor de reposición.

III. El neto de realización, que es el equivalente al precio normal de enajenación menos los gastos directos de enajenación y menos el porcentaje de utilidad que habitualmente se obtenga en su realización, si es superior al valor de reposición. (Art. 42, LISR)

Dentro de las obligaciones que se emiten específicamente para las personas morales, y con respecto a inventarios, el capítulo IX en su artículo 76 se menciona la de llevar contabilidad de acuerdo al CFF, su reglamento y el reglamento de la propia LISR, mencionado la fracc. I de este mencionado artículo, en la fracción IV, dice que además de formular un estado de posición financiera, deberá levantarse un inventario de existencias al final del ejercicio de acuerdo con las disposiciones reglamentarias establecidas en su artículo 110 que menciona que para elaborar el estado de posición financiera, deberá levantarse un inventario físico del total de sus mercancías al final del ejercicio o de manera parcial durante el periodo, con los ajustes correspondientes al final del mismo, y efectuar los registros de la misma y en la frac. XIV, se establece la obligación de llevar un control de inventarios de mercancías, materia prima, productos en proceso, terminados, conforme al sistema de inventarios perpetuos.

La obligación de levantar un inventario físico, también se establece para las personas físicas que realicen actividades empresariales, que sería el caso de muchas consideradas como PYMES, dicha obligación se encuentra en el artículo 110, frac. V de la LISR y el art. 192 del RLISR.

Con respecto al costo de ventas, el reglamento de la Ley del Impuesto Sobre la Renta (RLISR) en la sección III en el artículo 77, menciona que cuando los contribuyentes utilicen mercancías para uso propio, podrán deducir el costo siempre y cuando no se incluya en el costo de la mercancía vendida determinado.

El articulo 78 y 79, aclara la forma de utilizar el costeo absorbente sobre base de costos predeterminados, tanto para el costo de lo vendido como para los inventarios finales de mercancías que se enajenen y el artículo 82, otorga la decisión al contribuyente de utilizar cualquiera de los métodos de valuación de inventarios mencionados en la ley, a excepción de cuando se trate de 
mercancías que se le deba aplicar el método de costos identificados de acuerdo a las características mencionadas en el mismo artículo.

En lo que corresponde al Reglamento de la Ley del Impuesto Sobre la Renta, que es en donde se establecen reglas y definen criterios para la aplicación de la ley, en el capítulo II que habla de las deducciones, sección I de las deducciones en general, en el artículo 31, regula que las devoluciones, descuentos o bonificaciones que se efectúen con posterioridad al segundo mes del cierre del ejercicio en el cual se acumuló el ingreso o se efectuó la deducción, menciona una serie de reglas de como restarlas en diferentes situaciones, ya sea en el ejercicio en que se efectúan o en el que se acumula el ingreso.

En referencia al costo de lo vendido en la sección III, que comprende desde el artículo 77 al 84, regula lo referente a este concepto, hace mención de cómo proceder cuando el contribuyente utilice parte de sus inventarios para el consumo propio, mencionado un punto importante, que dice que el registro contable deberá ser acorde con el tratamiento fiscal (Ar, 77 RLISR). En general esta sección habla de la regulación sobre los sistemas de costeo, como el absorbente sobre la base de costos determinadas y sobre los métodos de valuación de los inventarios y determinación del costo de lo vendido.

\section{Metodología y técnicas}

El trabajo tiene un enfoque cualitativo. En las investigaciones cualitativas, consiste en que la muestra, la recolección y el análisis son fases que se realizan prácticamente de manera simultánea y van influyendo entre sí. Es conveniente para comprender desde la perspectiva de quienes lo viven, y cuando se buscan patrones y diferencias en estas experiencias y su significado. (Hernández y Mendoza, p9, 2018). La intencionalidad en el tipo de método de la investigación que se aborda es inductiva, el cual va de lo particular a lo general, de lo individual a lo universal. Trata de inducir una relación que incluya no sólo los casos particulares, sino que permita su generalización. Es decir, se apoya en los resultados de algunos casos particulares para establecer una relación general. En este caso, por ejemplo, de la muestra poblacional de las pequeñas empresas comerciales de la ciudad de Hermosillo, Sonora. El tipo de estudio es descriptivo, basado en cómo es y cómo se manifiesta un fenómeno y sus componentes. Su finalidad es recolectar datos que permitan conocer si las pequeñas empresas de Hermosillo, aplican las normas de información financieras y 
disposiciones fiscales a los rubros de costo de ventas, inventarios y por ende la determinación de resultados. El diseño de este estudio de investigación es de tipo no experimental, ya que se efectúa sin manipular deliberadamente variables, se observa el fenómeno tal como se dan en su contexto natural, para después analizarlos. De diseño no experimental, será la investigación longitudinal la acomodada para este tipo de investigación porque se recolectan datos en un momento, en este caso en el año de estudio, para poder describir variables y analizar su incidencia e interrelación, así como las actitudes y opiniones de los actores. En cuanto a la investigación de campo, se obtuvo información mediante un instrumento (cuestionario), en base a la escala de Likert, y se aplicó a empresas registradas el padrón del Sistema Empresarial Mexicano Hermosillo, Sonora. El cuestionario se valida previamente mediante prueba piloto de 20 cuestionarios, dando una escala combinado de .814 de fiabilidad en la escala de Alfa de Cronbach. La estructura consistió en 33 reactivos que fueron procesados en el sistema Statistical Package por the Social Sciences (SPSS) y expresados en gráficos tal y como se representan en el apartado de resultados. En el trabajo de campo, se aplicó la encuesta a una población de 200 empresas a las cuales se les envió de manera virtual, debido a la contingencia en que actualmente se encuentra el país, considerándose como avance del proyecto de investigación que se realiza.

\section{Resultados}

Se obtuvo respuesta de 77 empresas, presentando a continuación, los resultados con respecto a la observancia en la aplicación de las Normas de Información Financiera y disposiciones fiscales en el tema tratado. 


\section{Gráfica 2}

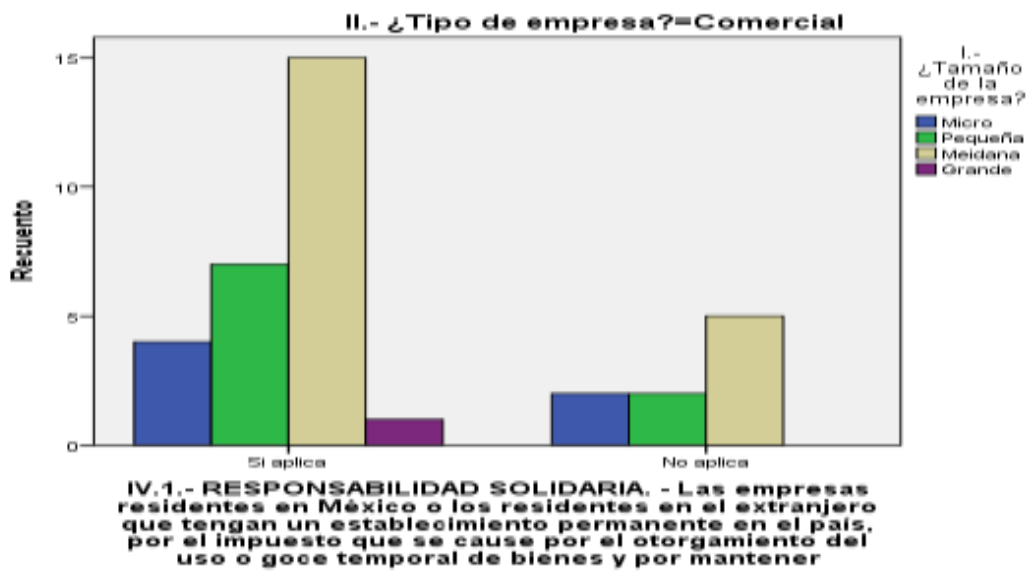

Fuente: Elaboración Propia

En la pregunta "RESPONSABILIDAD SOLIDARIA. Las empresas residentes en México o los residentes en el extranjero que tengan un establecimiento permanente en el país, por el impuesto que se cause por el otorgamiento del uso o goce temporal de bienes y por mantener" las empresas comerciales micro el $66.7 \%$, en las pequeñas el $77.8 \%$, en las medianas el $75 \%$ y en las grandes el 100\%; si aplica en las empresas residentes en México o los residentes en el extranjero que tengan un establecimiento permanente en el país, por el impuesto que se cause por el otorgamiento del uso o goce temporal de bienes y por mantener, con lo cual podemos decir que en un alto porcentaje de empresas si aplica esta norma.

\section{Gráfica 3}

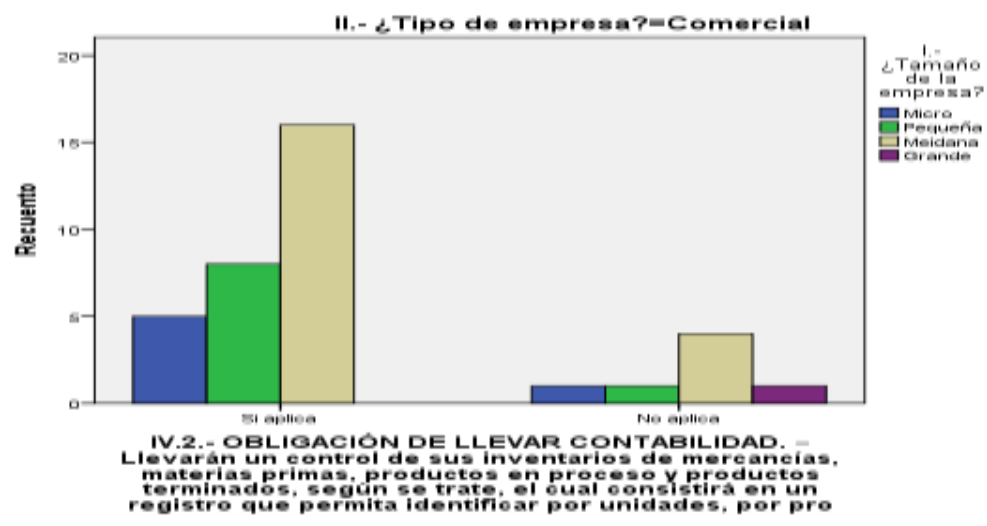

Fuente: Elaboración propia 
En la pregunta “OBLIGACIÓN DE LLEVAR CONTABILIDAD. Llevarán un control de sus inventarios de mercancías, materias primas, productos en proceso y productos terminados, según se trate, el cual consistirá en un registro que permita identificar por unidades", las empresas comerciales micro el $83.3 \%$, en las pequeñas el $88.9 \%$ y en las medianas el 80\%; si aplica el llevar un control de sus inventarios de mercancías, materias primas, productos en proceso y productos terminados, según se trate, el cual consistirá en un registro que permita identificar por unidades, con lo cual podemos decir que en un alto porcentaje de empresas si aplica esta norma.

\section{Gráfica 4}

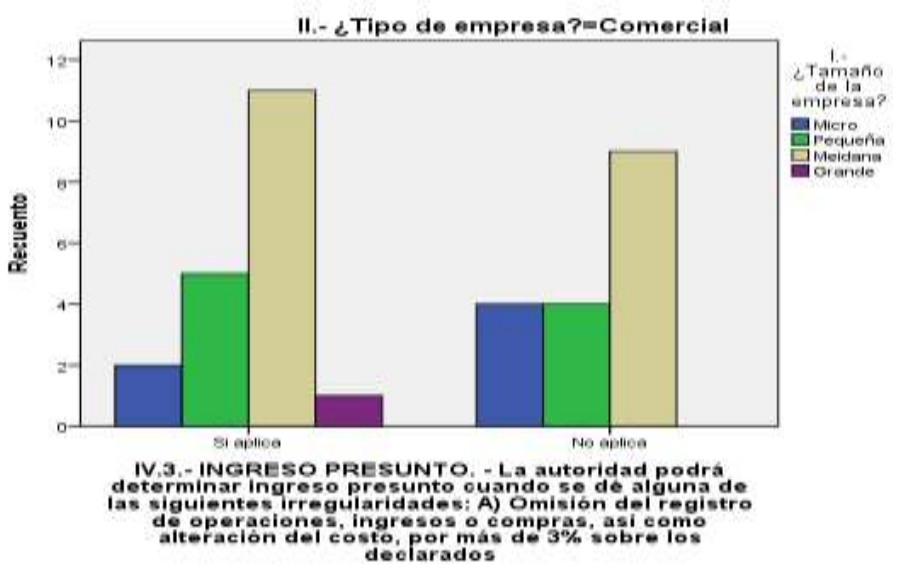

Fuente: Elaboración propia

En la pregunta "INGRESO PRESUNTO. La autoridad podrá determinar ingreso presunto cuando se dé alguna de las siguientes irregularidades: A) Omisión del registro de operaciones, ingresos o compras, así como alteración del costo, por más de 3\% sobre los declarados" las empresas comerciales micro el $33.3 \%$, en las pequeñas el $56.6 \%$, en las medianas el $55 \%$ y en las grandes el 100\%; si aplica la autoridad podrá determinar ingreso presunto cuando se dé alguna de las siguientes irregularidades: A) Omisión del registro de operaciones, ingresos o compras, así como alteración del costo, por más de $3 \%$ sobre los declarados, con lo cual podemos decir que en un alto porcentaje de empresas si aplica esta norma. 


\section{Gráfica 5}

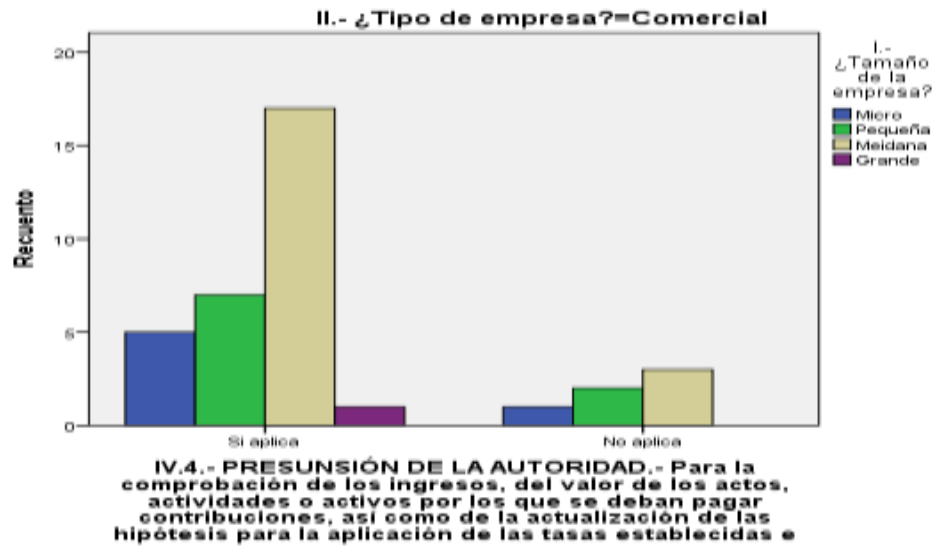

Fuente: Elaboración Propia

En la pregunta "PRESUNCIÓN DE LA AUTORIDAD. Para la comprobación de los ingresos, del valor de los actos, actividades o activos por los que se deban pagar contribuciones, así como de la actualización de las hipótesis para la aplicación de las tasas establecidas" las empresas comerciales micro el $83.3 \%$, en las pequeñas el $77.8 \%$, en las medianas el $85 \%$ y en las grandes el 100\%; si aplica para la comprobación de los ingresos, del valor de los actos, actividades o activos por los que se deban pagar contribuciones, así como de la actualización de las hipótesis para la aplicación de las tasas establecidas, con lo cual podemos decir que en un alto porcentaje de empresas cumple si aplica esta norma.

\section{Gráfica 6}

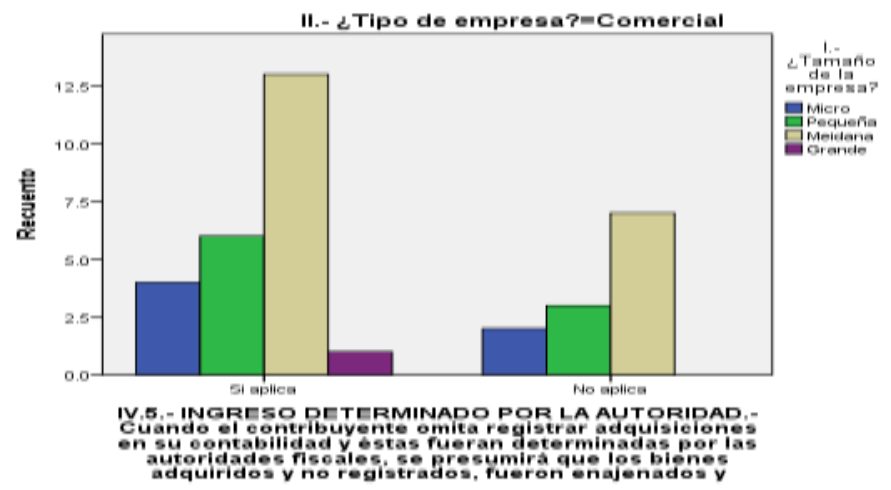

Fuente: Elaboración propia 
En la pregunta "INGRESO DETERMINADO POR LA AUTORIDAD. Cuando el contribuyente omita registrar adquisiciones en su contabilidad y éstas fueran determinadas por las autoridades fiscales, se presumirá que los bienes adquiridos y no registrados, fueron enajenados" las empresas comerciales micro el $66.7 \%$, en las pequeñas el $66.7 \%$, en las medianas el $65 \%$ y en las grandes el 100\%; si aplica Cuando el contribuyente omita registrar adquisiciones en su contabilidad y éstas fueran determinadas por las autoridades fiscales, se presumirá que los bienes adquiridos y no registrados, fueron enajenados, con lo cual podemos decir que en un alto porcentaje de empresas si aplica esta norma.

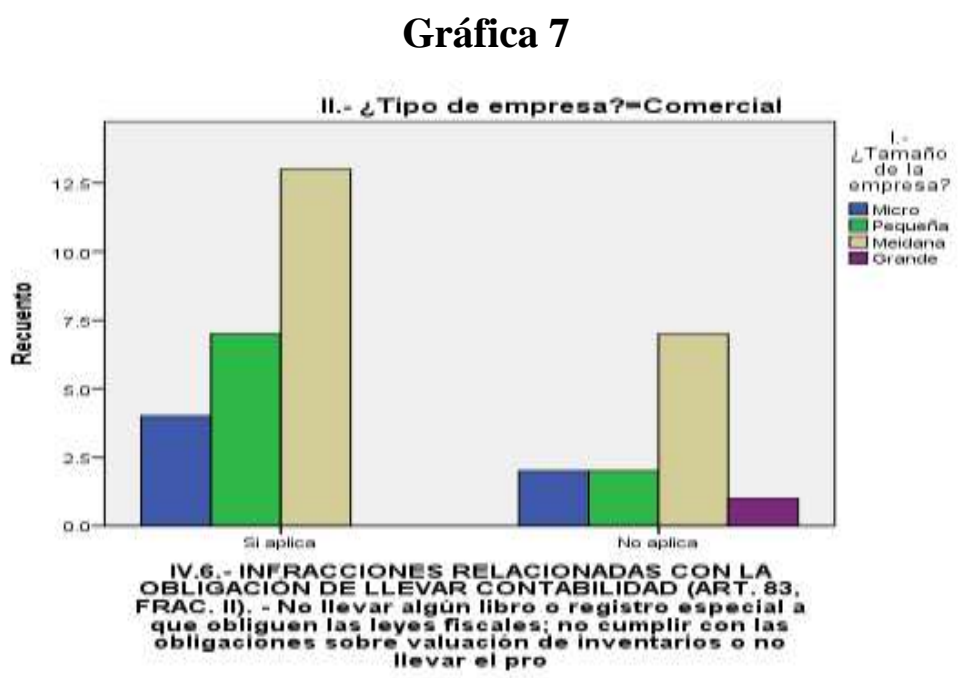

Fuente: Elaboración propia

En la pregunta "INFRACCIONES RELACIONADAS CON LA OBLIGACIÓN DE LLEVAR CONTABILIDAD (ART. 83, FRAC. II). No llevar algún libro o registro especial a que obliguen las leyes fiscales; no cumplir con las obligaciones sobre valuación de inventarios" las empresas comerciales micro el $66.7 \%$, en las pequeñas el $77.8 \%$ y en las medianas el $65 \%$; en las empresas si aplica no llevar algún libro o registro especial a que obliguen las leyes fiscales; no cumplir con las obligaciones sobre valuación de inventarios, con lo cual podemos decir que en un alto porcentaje de empresas si aplica esta norma. 


\section{Gráfica 8}

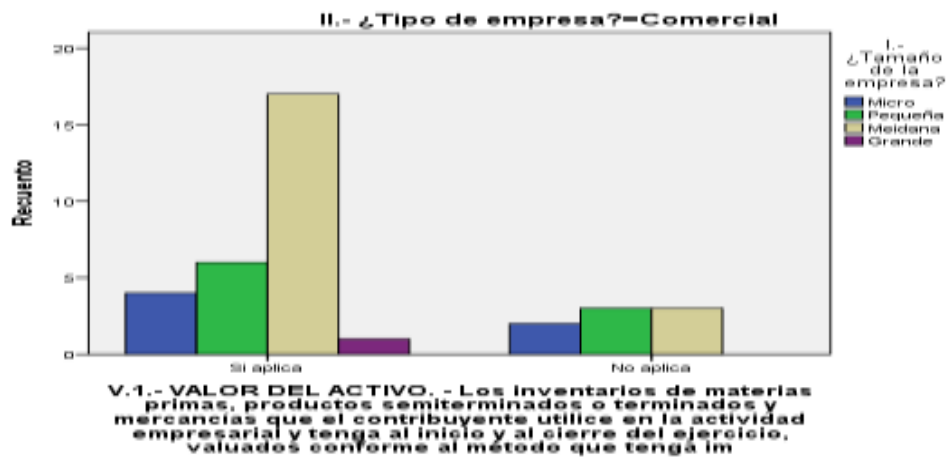

Fuente: Elaboración propia

En la pregunta "VALOR DEL ACTIVO. Los inventarios de materias primas, productos semiterminados o terminados y mercancías que el contribuyente utilice en la actividad empresarial y tenga al inicio y al cierre del ejercicio, valuados conforme al método que tenga implantado" las empresas comerciales micro el $66.7 \%$, en las pequeñas el $66.7 \%$, en las medianas el $85 \%$ y en las grandes el 100\%; si aplica que los inventarios de materias primas, productos semiterminados o terminados y mercancías que el contribuyente utilice en la actividad empresarial y tenga al inicio y al cierre del ejercicio, valuados conforme al método que tenga implantado, con lo cual podemos decir que en un alto porcentaje de empresas si aplica esta norma.

\section{Gráfica 9}

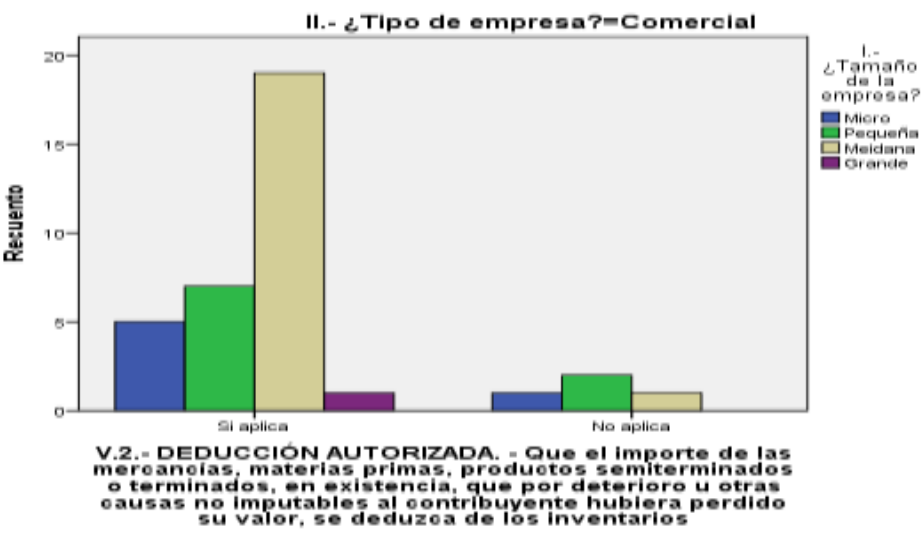

Fuente: Elaboración propia 
En la pregunta "DEDUCCIÓN AUTORIZADA. Que el importe de las mercancías, materias primas, productos semiterminados o terminados, en existencia, que por deterioro u otras causas no imputables al contribuyente hubiera perdido su valor, se deduzca de los inventarios" las empresas comerciales micro el $83.3 \%$, en las pequeñas el $77.8 \%$, en las medianas el $95 \%$ y en las grandes el 100\%; si aplica que el importe de las mercancías, materias primas, productos semiterminados o terminados, en existencia, que por deterioro u otras causas no imputables al contribuyente hubiera perdido su valor, se deduzca de los inventarios, con lo cual podemos decir que en un alto porcentaje de empresas si aplica esta norma.

\section{Gráfica 10}

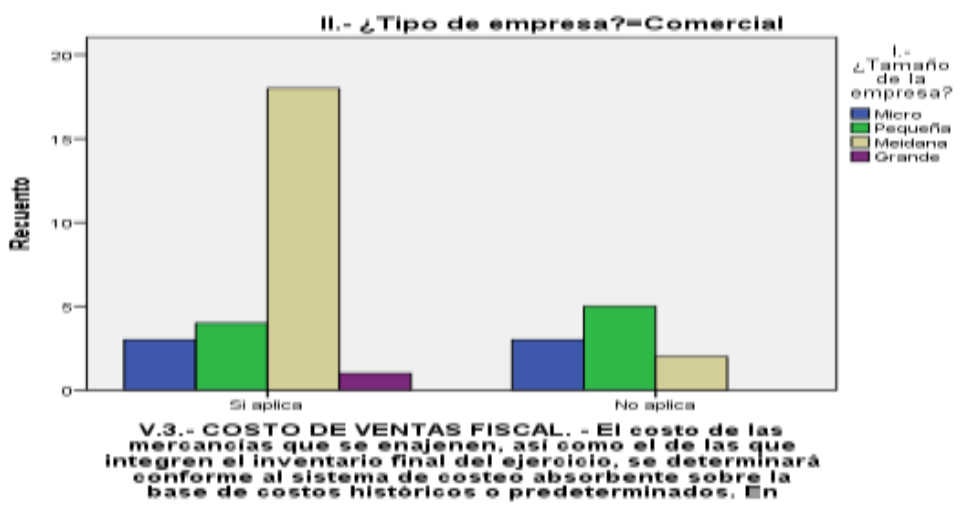

Fuente: Elaboración propia

En la pregunta "COSTO DE VENTAS FISCAL. El costo de las mercancías que se enajenen, así como el de las que integren el inventario final del ejercicio, se determinará conforme al sistema de costeo absorbente sobre la base de costos históricos o predeterminados" las empresas comerciales micro el $50 \%$, en las pequeñas el $44.4 \%$, en las medianas el $90 \%$ y en las grandes el 100\%; en las si aplica que el costo de las mercancías que se enajenen, así como el de las que integren el inventario final del ejercicio, se determinará conforme al sistema de costeo absorbente sobre la base de costos históricos o predeterminados, con lo cual podemos decir que en un alto porcentaje de empresas si aplica esta norma. 


\section{Gráfica 11}

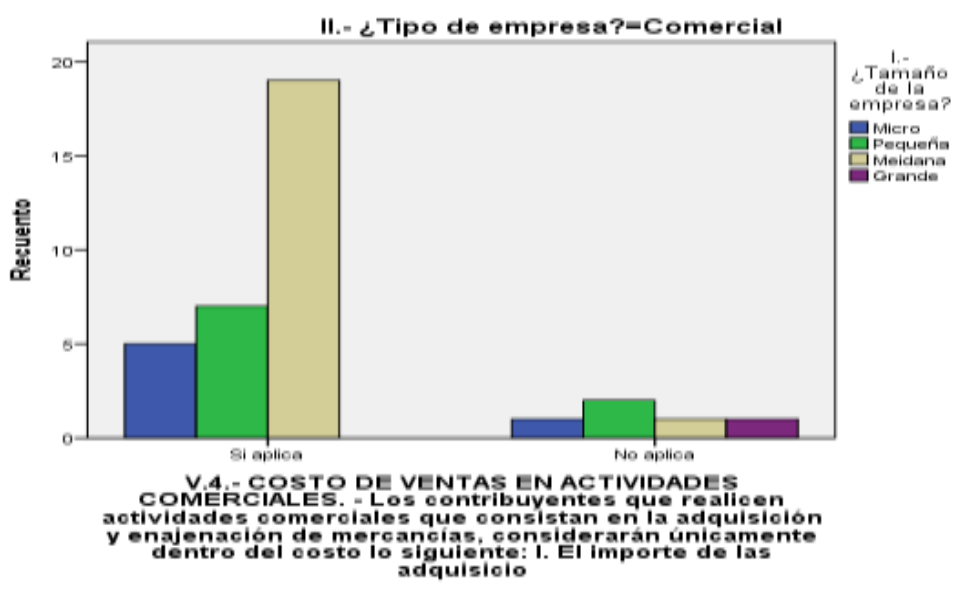

Fuente: Elaboración propia

En la pregunta "COSTO DE VENTAS EN ACTIVIDADES COMERCIALES. Los contribuyentes que realicen actividades comerciales que consistan en la adquisición y enajenación de mercancías, considerarán únicamente dentro del costo lo siguiente: I. El importe de las adquisiciones" las empresas comerciales micro el $83.3 \%$, en las pequeñas el $77.8 \%$ y en las medianas el 95\%; en las si aplica que los contribuyentes que realicen actividades comerciales que consistan en la adquisición y enajenación de mercancías, considerarán únicamente dentro del costo lo siguiente: I. El importe de las adquisiciones, con lo cual podemos decir que entre moderado y alto porcentaje de empresas si aplica esta norma. 


\section{Gráfica 12}

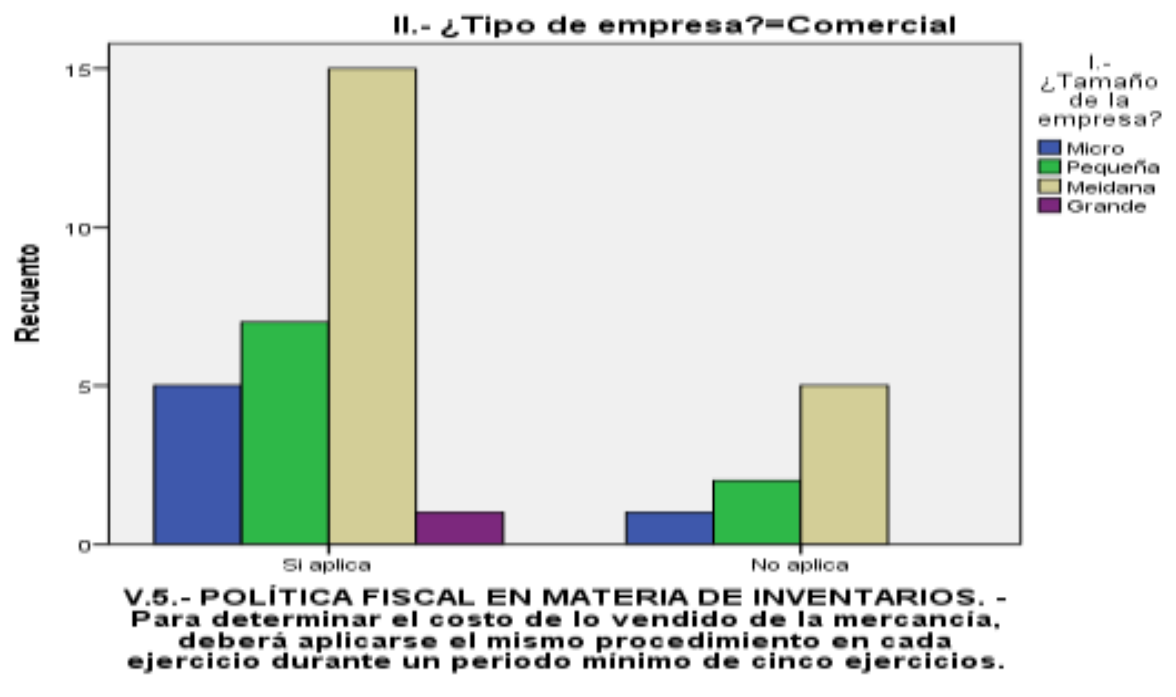

Fuente: Elaboración propia

En la pregunta "POLÍTICA FISCAL EN MATERIA DE INVENTARIOS. Para determinar el costo de lo vendido de la mercancía, deberá aplicarse el mismo procedimiento en cada ejercicio durante un periodo mínimo de cinco ejercicios" las empresas comerciales micro el 83.3\%, en las pequeñas el $77.8 \%$, en las medianas el $75 \%$ y en las grandes el 100\%; si aplica que para determinar el costo de lo vendido de la mercancía, deberá aplicarse el mismo procedimiento en cada ejercicio durante un periodo mínimo de cinco ejercicios, con lo cual podemos decir que en un alto porcentaje de empresas si aplica esta norma. 


\section{Gráfica 13}

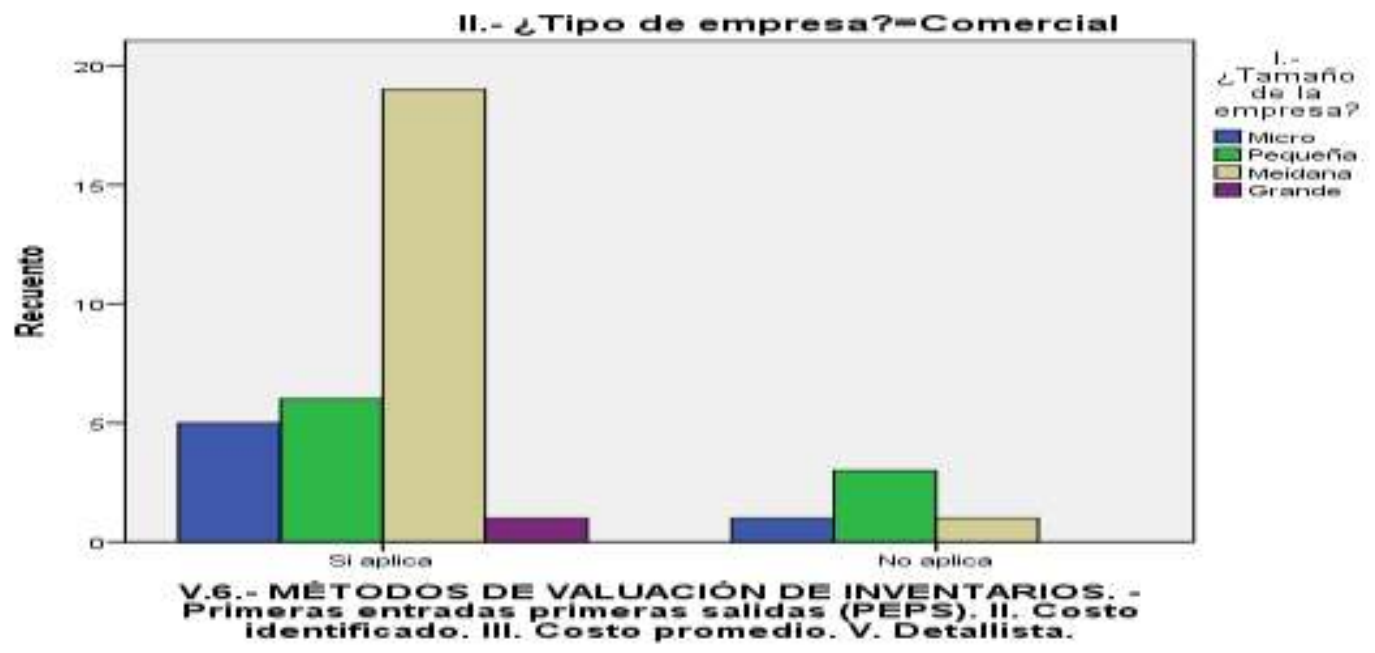

Fuente: Elaboración propia

En la pregunta "MÉTODOS DE VALUACIÓN DE INVENTARIOS. Primeras entradas primeras salidas (PEPS). II. Costo identificado. III. Costo promedio. V. Detallista" las empresas comerciales micro el $83.3 \%$, en las pequeñas el $66.7 \%$, en las medianas el $95 \%$ y en las grandes el 100\%; en si aplica el método de valuación de inventarios, con lo cual podemos decir que en un alto porcentaje de empresas si aplica esta norma. 


\section{Gráfica 14}

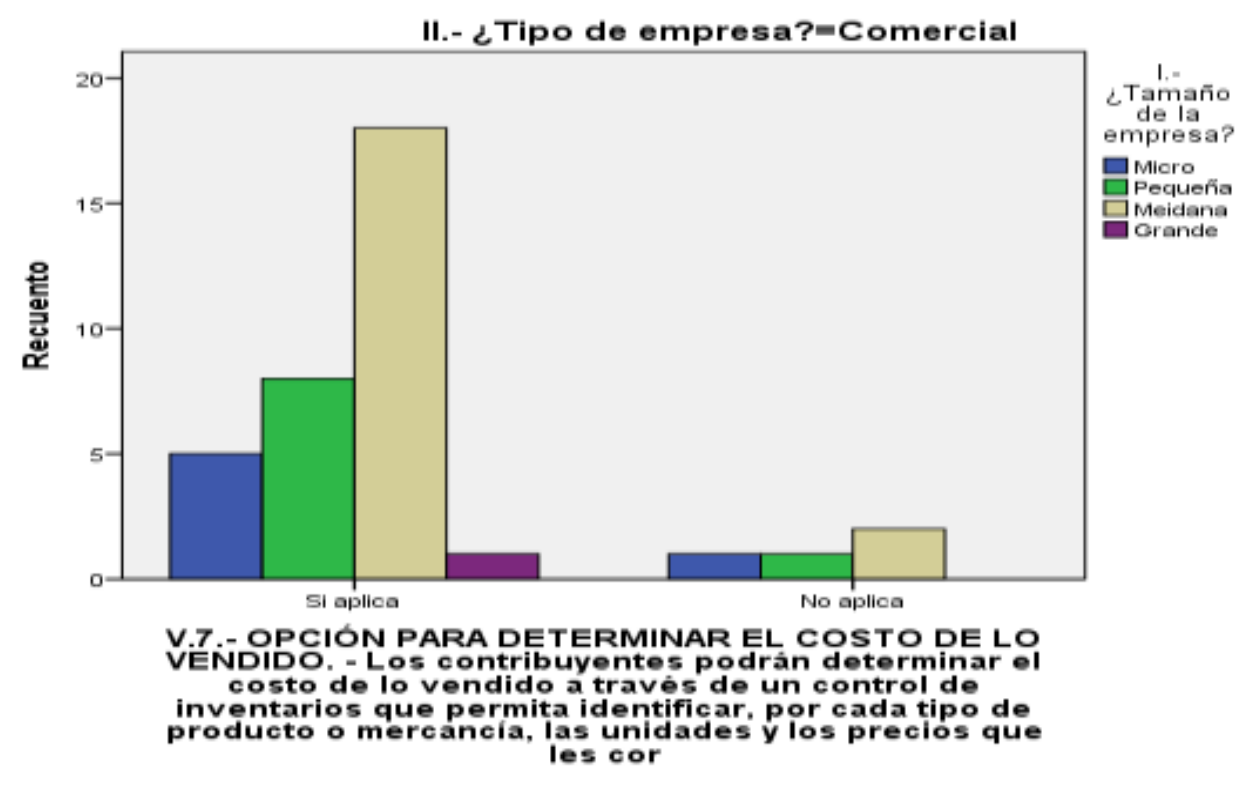

Fuente: Elaboración propia

En la pregunta “OPCIÓN PARA DETERMINAR EL COSTO DE LO VENDIDO. Los contribuyentes podrán determinar el costo de lo vendido a través de un control de inventarios que permita identificar, por cada tipo de producto o mercancía, las unidades y los precios que les corresponda" las empresas comerciales micro el $83.3 \%$, en las pequeñas el $88.9 \%$, en las medianas el $90 \%$ y en las grandes el 100\%; si aplica que los contribuyentes podrán determinar el costo de lo vendido a través de un control de inventarios que permita identificar, por cada tipo de producto o mercancía, las unidades y los precios que les corresponda, con lo cual podemos decir que en un alto porcentaje de empresas si aplica esta norma 


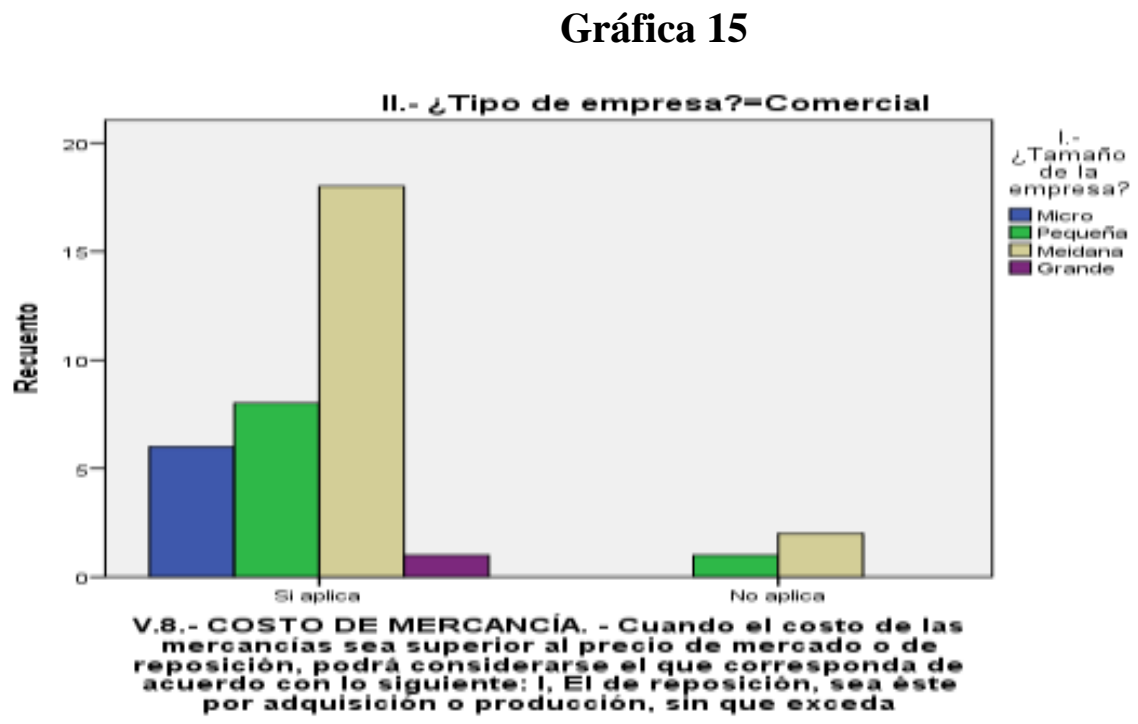

Fuente: Elaboración Propia

En la pregunta "COSTO DE MERCANCÍA. Cuando el costo de las mercancías sea superior al precio de mercado o de reposición, podrá considerarse el que corresponda de acuerdo con lo siguiente: I, El de reposición, sea éste por adquisición o producción, sin que exceda" las empresas comerciales micro el $100 \%$, en las pequeñas el $88.9 \%$, en las medianas el $90 \%$ y en las grandes el 100\%; si aplica que cuando el costo de las mercancías sea superior al precio de mercado o de reposición, podrá considerarse el que corresponda de acuerdo con lo siguiente: El de reposición, sea éste por adquisición o producción, sin que exceda, con lo cual podemos decir que en un alto porcentaje de empresas si aplica esta norma.

\section{Conclusiones}

Las pequeñas empresas y en general las MIPYMES, es de sobra conocido, en base a la gran diversidad de estudios que así lo manifiestan, que presentan una gran cantidad de problemas para su crecimiento, subsistencia, derivado de múltiples factores, como mala administración, falta de profesionalismo de sus propietarios, administradores, falta de estructura financiamiento, etc., lo anterior se agrava con el impacto de la pandemia provocada por COVID 19, que afecta en la economía mundial, siendo este sector económico, el más vulnerable. Por eso se hace importante analizar también en qué condiciones de aplicación de la normatividad contable y fiscal se 
encuentran con respecto a uno de los factores más importantes dentro de las organizaciones, como le es el recurso de los inventarios y la determinación del costo de ventas, conocer si lo hacen apegada a dicha normatividad.

Se considera que se cumple con los objetivos del trabajo al identificar las disposiciones fiscales aplicables al control y valuación de los inventarios, en las pequeñas y medianas comerciales, así como la obtención del costo de ventas empresas en Hermosillo, Sonora, y que las PyMES utilizan dichas disposiciones legales y de normatividad inherente, base para la elaboración de información financiera como queda demostrado en el texto del documento.

Para un debido control de inventarios de acuerdo con lo dispuesto en materia fiscal y como parte del control interno, se requiere de recursos humanos adecuadamente capacitados para tal fin, de recursos económicos y tecnológicos para hacerlo y el debido conocimiento de la norma. Se considera que las pymes cumplen con estos factores ya que entre el $80 \%$ y $100 \%$ de las empresas consultadas así lo consideran. De igual manera cuentan con los registros físicos y digitales en cuanto a control de inventarios, realizan conteos físicos y su debida valuación en base a alguna de las fórmulas de asignación del costo establecida la Ley del Impuesto Sobre la Renta y su Reglamento, y en base al código fiscal de la federación y su reglamento.

En relación a la determinación del costo de ventas las pymes reconocen y manifiestas que se realiza en base a la normatividad contable establecida, y observando de igual manera, lo dispuesto por la LISR, Código Fiscal de la Federación y su reglamento, que utilizan un método de costo reconocido y que la determinación de sus costos de ventas lo hacen tomando en cuenta el control de inventarios.

La recomendación se da para las pequeñas empresas que son las que menos utilizan estos factores de determinación de resultados y presentación de información financiera, incluso de acuerdo con la encuesta aplicada por INEGI, manifiesta que cerca del $40 \%$ no llevan un proceso contable para el control de ingresos y gastos, incluyendo los costos, considerando un área de oportunidad para profesionalizar el control de este tipo de empresa. 


\section{Referencias}

Bernal Cesar A. (2010) Metodología de la Investigación, administración, economía, humanidades y ciencias sociales. 3ra. Edición, Ed. Pearson Educación, Colombia

Calleja Bernal Francisco Javier, Calleja Mendoza Ana María, (2015) Contabilidad 1. Segunda Edición Editorial Pearson Educación de México, S.A. México

CINIF, (2020), Normas de Información Financiera, Ed. Consejo Mexicano de Normas de Información Financiera, A.C. México

García Colín, Juan, (2014) Contabilidad de Costos, 4ta Edición, Editorial Mc Graw Hill, Interamericana Editores, S.A. México

Hernández Sampieri Roberto, Mendoza Torres Christian Paulina (2018) Metodología de la Investigación. Las rutas cuantitativas, cualitativas y mixta. Ed. Mc Graw Hill. México.

Romero López, Javier. (2014) Principios de Contabilidad 6 ${ }^{\text {ta }}$. Edición. Editorial Mc. Graw Hill Interamericana Editores, S.A de C.V. México

https://www.gob.mx/ secretaria de economía https://www.inegi.org.mx/ Censos económicos 2019 https://www.pulsopyme.com/como-operan-en-la-actualidad-las-pymes-en-mexico/ https://www.ifac.org/knowledge-gateway/preparing-future-ready-professionals/discussion/lasimplicaciones-del-covid-19-en-la-entrega-de-informaci-n-financiera

https://inegi.org.mx/contenidos/saladeprensa/boletines/2020/OtrTemEcon/ECOVIDhttps://www2.deloitte.com/content/dam/Deloitte/cr/Documents/audit/documentos/IFRSin-Focus--Enfermedad-COVID-19.pdfIE_DEMOGNEG.pdf https://www.mazars.mx/Pagina-inicial/Insights/Covid-19-Reflexiones-de-Mazars/ImplicacionesContables-en-los-EEFF-2019-2020 https://www.cinif.org.mx/anuncios/reporte/Reporte_Tecnico_31-2016.pdf http://www.diputados.gob.mx/LeyesBiblio/pdf_mov/Constitucion_Politica.pdf http://www.oas.org/juridico/spanish/mesicic3_mex_anexo8.pdf http://www.diputados.gob.mx/LeyesBiblio/pdf_mov/Ley_General_de_Sociedades_Mercantiles.p $\underline{\mathrm{df}}$ 
Arreguin Ruiz, Javier, 8/10/2020 https://www.asnews.mx/noticias/aprendiendo-del-codigo-fiscalde-la-federacion retomado el 30/03/2021

http://www.diputados.gob.mx/LeyesBiblio/pdf/LISR_081220.pdf

Como citar este articulo

Calles, F., Noriega, A., \& Félix Enríquez, S. (2021). CONOCIMIENTO Y APLICACIÓN DE LAS DISPOSICIONES LEGALES-FISCALES RELACIONADAS CON EL COSTO DE VENTAS E INVENTARIOS EN LAS PEQUEÑAS Y MEDIANAS EMPRESAS (PYMES) COMERCIALES, EN HERMOSILLO SONORA. Revista dDe Investigación Académica Sin Frontera: División de Ciencias Económicas Y Sociales, (35). https://doi.org/10.46589/rdiasf.vi35.380

https://revistainvestigacionacademicasinfrontera.unison.mx/index.php/RDIASF/article/view/380

o Dia net

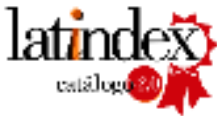

ff uifactor REDIB

Citefactor

in LatinREv

Neliti - Indonesia's Research Repository
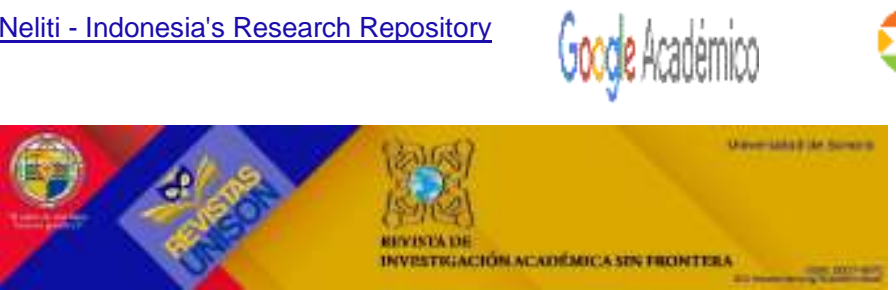